rev.relac.int.estrateg.segur.9(1):111-129,2014

\title{
AUTORITARISMO Y DEMOCRACIA EN AMÉRICA LATINA: DOS POLOS DE RACIONALIDADES HEGEMÓNICAS SOCIALES, POLÍTICAS Y CULTURALES*
}

\author{
Juan María Cuevas Silva**
}

\section{RESUMEN}

En el presente escrito se desarrollan algunos elementos iniciales del autoritarismo en América Latina, específicamente de su proceso dentro del sistema de la encomienda, analizando cómo desde allí se comenzó a implementar un sistema autoritario que se ha enraizado en el pensamiento de las ideas políticas latinoamericanas. En un segundo apartado se exponen algunas de la contradicciones del proceso democratizador que ha asumido América Latina, como un sistema que se implementa desde las burguesías criollas pero con un tinte que en el fondo repite el esquema del autoritarismo. En este sentido se resaltan los principios que deben distinguir a un Estado Democrático, el significado de

* El artículo es resultado de investigación de la primera fase del proyecto "Expresiones de la intersubjetividad a partir de la relación educación y ciudadanía digital", de la Universidad de San Buenaventura Bogotá, código CID 0006-002.

** Licenciado en Filosofía y Especialista en Pedagogía y Docencia Universitaria de la Universidad de San Buenaventura - Bogotá. Magister en educación de la Universidad Pedagógica Nacional de Colombia. Doctorante en Procesos Sociales y Políticos en América Latina de la Universiad de Arcis, Santiago de Chile. jumacusi@gmail.com. 
la ciudadanía, la injerencia del sistema capitalista e industrial, así como las distintas dinámicas que han ayudado a que se implemente más un autoritarismo político que uno democrático. El objetivo fundamental es hacer un acercamiento investigativo a lo que ha significado la construcción de ciudadanía, desde el contexto del autoritarismo y la democracia en América Latina, esto dentro del marco de la investigación "expresiones de la intersubjetividad a partir de la relación educación y ciudadanía digital" Ilevada a cabo en la Universidad de San Buenaventura-Bogotá.

Palabras clave: Autoritarismo, democracia, encomienda, ciudanía, Estados Modernos, democratización, desarrollo, subdesarrollo.

\title{
AUTHORITARIANISM AND DEMOCRACY IN LATIN AMERICA: TWO EXTREMES OF SOCIAL, POLITICAL AND CULTURAL HEGEMONIC RATIONALITIES
}

\begin{abstract}
In this article some early elements of authoritarianism in Latin America are considered, specifically their process within the encomienda system. First, an analysis is made how from there, an authoritarian system started and has taken root in the thinking of Latin American politics. The second section describes some of the contradictions of the democratic process that Latin America has taken on, as a system that is implemented from the local capitalistic middle class, with a scheme that repeats the pattern of authoritarianism. In this respect, emphasis is made of the principles that should tell apart a Democratic State, the meaning of citizenship, the connotation of the capitalist and industrial system, as well as the various dynamics that have helped implement authoritarianism more political than democratic. The main objective is to formulate an investigative approach to what has meant the creation of citizenship, from the context of authoritarianism and democracy in Latin America; all this within the framework of the research document "expressions of intersubjectivity from the relation between education and digital citizenship ", carried out at the Universidad of San Buenaventura, in Bogota.
\end{abstract}

Keywords: Authoritarianism, democracy, encomienda, citizenship, Modern States, democratization, development, underdevelopment.

\section{AUTORITARISMO E DEMOCRACIA NA AMÉRICA LATINA: DOIS PÓLOS DE RACIONALIDADES HEGEMÔNICAS SOCIAIS, POLÍTICAS E CULTURAIS}

\section{RESUMO}

Neste trabalho desenvolvem-se alguns elementos iniciais do autoritarismo na América Latina, especificamente sobre o processo dentro do sistema da encomenda e analisa-se como a partir 
daí começou a se estabelecer um sistema autoritário que foi enraizado no pensamento político da latino-americana. Na segunda seção, descrevem-se algumas das contradições do processo democrático que a América Latina assumiu, como um sistema que se desenvolve nas burguesias crioulas, mas com um tom que basicamente repete o padrão do autoritarismo. Neste sentido, destacam-se os princípios que devem distinguir um Estado democrático, o significado de cidadania, a interferência do sistema capitalista e industrial, assim como as várias dinâmicas que ajudaram a que se estabeleça mais um autoritarismo político do que um democrático. $\mathrm{O}$ objetivo principal é pesquisar sobre o que significou a construção da cidadania, considerando o contexto do autoritarismo e da democracia na América Latina no âmbito do trabalho de pesquisa "Expressões da intersubjetividade a partir da relação educação e cidadania digital", realizado na Universidade de San Buenaventura, em Bogotá.

Palavras-chave: Autoritarismo, encomenda, cidadania, democratização, desenvolvimento, subdesenvolvimento

\section{INTRODUCCIÓN}

El proceso de construcción de los Estados Latinoamericanos ha sido conjugado por diversos elementos sociológicos, culturales, políticos, económicos y hasta religiosos, que le han permitido a América Latina afrontar las dinámicas históricas de la conquista, la colonia, la modernización de los Estados, la imposición de sistemas económicos, y el establecimiento de formas de gobierno que se han conjugado entre lo autoritario y lo democrático, fenómeno que ha permitido una comprensión errónea entre las funciones y sentido de lo que es el Estado, el gobierno y el régimen político, tres aspectos que son distintos y diferentes y que al mismo tiempo exigen que se aborden desde ciencias como la sociología, la historia y la política. Por otra parte, el establecimiento y fortalecimiento de los regímenes políticos, la instalación de los modelos de Estado, así como la instauración de formas políticas, en el caso de América Latina, han favorecido la tensión preponderante entre autoritarismo y democracia. En este escrito se abordará el problema del autoritarismo y su tensión con la democracia, con anotaciones históricas desde la conquista hasta la implantación del modelo democrático, el por qué hay democracias incompletas en América Latina y cuáles son las hegemonías fracasadas, y cómo desde estos ámbito se ha tejido y se teje un concepto y una visión sociedad, política, cultura y educación. Antes de abordar dentro de la investigación anteriormente citada el problema de la ciudadanía digital, es indispensable estudiar e investigar sobre el sentido de la política en el contexto latinoamericano, en un inicio desde las relaciones y tensiones entre autoritarismo y democracia.

\section{HITOS HISTÓRICOS DE AUTORITARISMO}

"Los países latinoamericanos son actualmente el resultado de la sedimentación, yuxtaposición y entrecruzamiento de tradiciones indígenas (sobre todo en las áreas 
mesoamericana y andina), del hispanismo colonial católico y de las acciones políticas, educativas y comunicacionales modernas" (García Canclini, 1989, p. 71)

Las distintas concepciones de autoritarismo y sus dinámicas han permitido hacer estudios serios y profundos sobre sus características e influencias, específicamente en la cultura latinoamericana. Para iniciar y comprender lo que ha sido el autoritarismo en nuestra región se enuncian a continuación dos de los planteamientos de Klaveren sobre los principios para el estudio del autoritarismo., citado por Freddy Domínguez Nárez en "Legitimidad y Gobernabilidad en el autoritarismo" (2004):

Klaveren ha organizado las corrientes de estudios en cuatro grandes tradiciones o escuelas interpretativas 1) la corriente del cabio o del desarrollo político, donde el autoritarismo es considerado "como un fenómeno dirigido a la transición hacia la modernidad"; el autor distingue dos tendencias: la optimista, según la cual "el crecimiento económico auto-sostenido aportaría al país en vía de desarrollo la estabilización democrática, y la pesimista, según la cual, el autoritarismo es engendrado por el proceso de modernización". 2) La corriente histórico-culturalista, que nos dice que la fuente del autoritarismo contemporáneo de América Latina se encuentra "en la herencia precolombina, la tradición ibérico-católica y el sistema actual” (Domínguez Nárez, 2004:24-25)

De acuerdo con los planteamientos anteriores, se desarrollarán las siguientes ideas, partiendo del principio que la colonia y la conquista engendran en su seno principios y fundamentos del autoritarismo comprendido y entendido como aquel fenómeno que "designa una manifestación degenerativa de la autoridad, que se apoya de manera suficientemente permanente sobre la utilización reiterativa de medios coercitivos; es un abuso de autoridad tanto individual como estructural, y tiende a obstaculizar las normas y valores socio-culturales sistematizados en un contexto prescriptivo" (Dominguez Nárez, 2004:12)

La historia de América Latina ha estado matizada entre las tensiones del dominio religioso y los brotes del militarismo; se ha dinamizado entre los lazos de la esclavitud y los ideales de la libertad; se ha cimentado entre las ilusiones de la independencia y las políticas de la homogeneización; se ha forjado en la controversia entre la igualdad y la desigualdad, la equidad e inequidad, la justicia y la injusticia, la riqueza y la pobreza. Todo esto enraizado en procesos profundos de autoritarismo ${ }^{1}$, que en momentos históricos reales se han presentado como sistemas coloniales, luchas criollas, dictaduras, populismos y también disfrazados de democracia. La pregunta es: ¿qué sentido han tenido estos sistemas en los cuales las promesas de libertad, autonomía e independencia han sido el eje transversal tanto de los defensores de la democracia como de los autoritaristas? Desde los planteamientos de José Ignacio García Hamilton (2011):

1. Es importante aclarar que en este escrito no se profundizará en el concepto de autoritarismo, el cual se encuentra bien desarrollado en las ideas de Juan Linz, Jean Francois Bayrt o Guillermo O’Donnell. 
Partimos del supuesto de que existe en nuestras sociedades una cultura política autoritaria, entendiendo por tal un conjunto de creencias, sentimientos, ideas, opiniones, esperanzas y actitudes que hacen posibles la aceptación de tutelajes y la renuncia al autogobierno, situaciones que a menudo conducen, no solamente a negar derechos de minorías, sino también a ejercer sobre ellas I crueldad y el genocidio. (García Hamilton, 2011, p. 20)

Esta postura nos permite abordar el fenómeno del autoritarismo como un sistema que marca la esencia del ser latinoamericano, es decir, como una condición heredada por la cultura latinoamericana es sentirse amedrentada por los sistemas de poder implantados en cada una de las repúblicas, naciones y países de la región. Aspecto que no le ha permitido correlacionar, entrecruzar, y comprender lo político, lo cultural y lo económico, así como lo social e identitario, como un proceso holístico y unitario, más bien, por el contrario, estos aspectos están divorciados los unos de los otros, funcionan como ejes independientes y asistemáticos, que llegan a ser coercitivos. Este fenómeno tiene uno de sus inicios en el proceso de la conquista. Así, la apertura de toda la dinámica autoritaria, desde la conquista, se encuentra en el sistema de la encomienda (García Hamilton, 2011, p. 21 ss), la cual sirvió para utilizar como método para fortalecer el proceso de evangelización, o desde una perspectiva más secular, para garantizarle a la Iglesia Católica convertirse en el modelo hegemónico, moral, social y de creencia en un territorio con un pueblo "nuevo e ignorante", que por lo mismo se podía convertir en un dominado y esclavizado. La encomienda, entendida como sistema de dominio y autoritarismo, deja ver claramente cómo el encomendero se convierte en amo y señor, que protegido por el sistema político y jurídico, abusa de sus poderes y capacidad de dominio. Es interesante cómo Iglesia, en la voz de los dominicos Antonio de Montesinos y Fray Bartolomé de las Casas, denuncian los abusos e injusticias de los encomenderos (García Hamilton, 2011). A lo largo del proceso de conquista, y con la llegada de distintos conquistadores, el encomendero fue reemplazado:

Con el tiempo sobrevino la figura del corregidor, un funcionario público que reemplazaba al encomendero privado en su papel, pero que frecuentemente llegó a opacar, por su crueldad y su codicia, el rol que habían desempeñado los titulares de repartimientos. Para los indígenas, las diferencias entre esos regímenes no pasaban de sutilezas jurídicas que no cambiaban su condición real de explotado y maltratado. (García Hamilton, 2011, p. 25)

El sistema de la encomienda no se implantó con el objetivo de evangelizar sino de usufructuar y obtener beneficios económicos desde la fuerza de trabajo del habitante natural de la América aborigen, hecho que nos permite afirmar que antes que evangelizar estaba era la intención de usufructuar, más bien, en palabras de García Hamilton (2011):

Al margen de las teorizaciones sobre la naturaleza del modo de producción que oprimía al aborigen, nos interesa destacar a cá que la encomienda no nació, entonces, con el fin de evangelizar a los naturales. El proceso fue más bien inverso: los repartimientos fueron iniciados por los españoles en América, con el objetivo de extraer beneficios económicos 
del trabajo de los indígenas; y muy lejos estuvo el ánimo de Cortés, Roldán o Pizarro la finalidad misericordiosa. La Corona a posteriori, cuando vio que no podía impedirlos, impuso a los encomenderos, a cambio del disfrute de las labores de los indios, la obligación de cristianizarlos. (García Hamilton, 2011, p. 28)

Según estas dinámicas históricas, la fuerza de dominio y control, sobre el aborigen y su fuerza de trabajo son el inicio de la fragmentación de lo económico y lo social, lo político y lo cultural en el territorio latinoamericano, de tal forma que desde el intento de occidentalizar las indias, se ha fraguado un pensamiento y una convicción desastrosa para la cultura latinoamericana, una lucha de clases en la que "la tragedia de la 'plebe' latinoamericana es que no puede fundar su desarrollo en lo que es la base del desarrollo capitalista: el trabajo" (Lechner, 1977, p. 51), desde la encomienda el valor de la fuerza de trabajo ha sido manejada desde sistemas autoritarios que imponen sus reglas, que fomentan las distintas problemáticas sociológicas, el malestar de la cultura, desde una subjetividad minusvalorada y un ejercicio intersubjetivo matizado por los sistemas de dominio y control desbocados por la ambición y la esclavitud del otro, que promueven la crueldad y la violencia, la desigualdad y la inequidad, el malestar y el resentimiento social. Esto permite ver también que el autoritarismo no es propio solamente de los sistemas absolutistas, dictatoriales y populistas que caracterizaron al siglo XX en Occidente y América Latina, por no nombrar otros territorios, sino que este fenómeno viene desde el momento en que llegó y nos invadió la mentalidad española a nombre de Europa y del Catolicismo reinante en la Península Ibérica pero decadente en otras regiones.

La dinámica histórica nos lleva a analizar si realmente el sistema implementado con el objetivo de evangelizar y cristianizar a los indígenas, ha permitido, o mejor, permitió, la construcción de un territorio que bajo el mandamiento del Amor, el respeto y la tolerancia se propone hacer valer los principios de la libertad, la fraternidad y la justicia, así como la igualdad. Pareciera que no, que por el contrario las dinámicas socio-culturales, desde el manejo e influjo político en la región Latinoamericana naciente, más bien fundamentó violencias y crueldades, exterminio y desolación. Además de caracterizarse este fenómeno por la implantación imperativa de una religión a la cual los indígenas se adhirieron pero de manera externa, porque ellos seguían con sus supersticiones y creencias, así como también se encuentran hechos socio-políticos en los que se promulga la paz pero se hace la guerra (García Hamilton, 2011). Las dinámicas socioculturales, político-económicas y cívico-religiosas de la conquista se pueden ver como un juego entre el deseo e ímpetu por perpetuar el feudalismo y el catolicismo, por mantener un sistemas en el que el teocentrismo y la monarquía sean los modelos y paradigmas preponderantes para un región que ha sido conquistada y arrebatada de sus sistemas originales, que debe enmarcarse dentro del proceso de homogeneización eurocéntrico.

El proceso de la conquista tuvo su inicio, albor y decaimiento, etapas de las que aún se sienten herencias fuertes dentro de los procesos de configuración, cultural, social y política de la región latinoamericana. Así: 
Si el absolutismo que florecía en España al tiempo del descubrimiento en América era uno de los elementos que consolidaba la unidad de los reinos y la creación del estado Nacional moderno, el estatismo fue instrumento mediante el cual la metrópoli subordinaba los recursos y las producciones de las colonias a las necesidades económicas de la península. (García Hamilton, 2011, p. 59)

Esto facilita la comprensión de una región que, hasta el día de hoy, permite que sus interacciones políticas, económicas y sociales estén intervenidas y condicionadas por el Estado. La encomienda favorece un estatismo cultural, social, económico y político en la región latinoamericana, de tal forma que los indígenas, esclavos del amo español, son los responsables de fomentar la riqueza de su amo, estar al servicio de una persona que venía a estas tierras a servirse de los indígenas.

La tenencia de indígenas para el trabajo fue en la América Hispana como la tierra pública en la Roma Imperial, el carbón de la Inglaterra del siglo XIX o el petróleo y la tecnología cibernética en la actualidad: quienes los poseen son ricos y poderosos, los que carecen de ellos son pobres y débiles.

La aspiración de todo español en las Indias era llegar a tener indios encomendados. Lo dice bien a las claras en una carta a la Corona del Virrey del Perú, Don Luis de Velazco, en 1597: "los peninsulares no vienen acá a trabajar, sino a servirse de los indios y sus hacendillas" (García Hamilton, 2011, p. 60)

La conquista ha convertido a la región latinoamericana en ese territorio de riquezas, donde los extranjeros vienen y nos dominan con sus ínfulas de poder y de control, nos venden su idea de mejor clase y estirpe, y el habitante se deja intimidar, se aturde física y mentalmente y se siente bien sirviéndole al amo, en otras palabras, el autoritarismo implementado e implantado en América Latina va más allá de lo político, se convierte, desde esta perspectiva, en un ejercicio socio-cultural predominante. $\mathrm{Y}$ es precisamente en este contexto y por los malestares que generó el dominio conquistador, colonial y encomendero por el que se gestó el movimiento de la independencia, el deseo de ser autónomos e independientes, tejiéndose así un sueño y una ilusión por ser dueños de lo nuestro, administradores de lo nuestro, capaces de saber generar bienestar desde lo nuestro, lógicamente todo esto con influencia externa: la revolución francesa.

La historia de América Latina a partir de finales del siglo XVIII y el siglo XIX va a estar enmarcada por ese afán de ser libres y autónomos, tarea que fue asumida por las élites criollas de los países latinoamericanos. Así, se gestaron enfrentamientos contra la Corona Española, se Ilevaron a cabo batallas en las que un autoritarismo fue desterrado, pero con un aliciente, se le daba la bienvenida a un nuevo sistema de dominio y control, a una nueva forma de esclavitud que ya no sería orientada y liderada por foráneos sino por criollos, es decir, por hombres que nacidos en América Latina habían tenido la fortuna de ser hijos de españoles con indígenas o personas nacidas aquí. Estos criollos eran cultos, habían viajado a tierras europeas y habían conocido el sueño de la Revolución Francesa, los ideales de Napoleón y una serie de filosofías que trajeron 
afanadamente para poder dar libertad a un pueblo que la clamaba con desespero. A este clamor se le unían factores de todo tipo: religiosos, económicos, sociológicos, políticos, económicos, educativos, en los cuales juega un papel importante la mentalidad latinoamericana cimentada en lo religioso y lo dependiente. Así, surge un cuestionamiento: iprocesos de independencia para qué? La pregunta va encaminada al sentido socio-político de los movimientos libertarios e independentistas, es decir, a su papel dentro de las estructuras occidentalizadas basadas en la democratización de los Estados. Si bien es cierto que a lo largo de tres siglos y medio largos, la colonia y la conquista habían dominado por medio de los encomenderos, los virreyes, lo gobernantes implantados por la Corona bajo un régimen autoritario, con la bendición del dominio cristiano-católico, ¿cuál era el sistema bajo el cual los líderes y próceres liberarían a los latinoamericanos? Muy sencilla la respuesta: la democracia. Sí, ha sido sencilla la respuesta, pero lo complejo es comprender cómo se llevó a cabo desde estos movimientos, cómo se dio inicio a un divorcio pero al mismo tiempo a un matrimonio, entre libertad y esclavitud, autoritarismo y democracia, economía y política, religión y sociedad con política incluida, entre otros aspectos que son relevantes para configurar la cultura latinoamericana.

\section{LA DEMOCRACIA: MODELO CONTRADICTORIO EN AMÉRICA LATINA}

América Latina se ha adentrado en el discurso democrático como esperanza para la constitución de sus Estados libres, autónomos e independientes. Desde los movimientos de independencia hasta hoy, la clase política dominante ha hecho caso al modelo eurocéntrico y nortamericanizante de la democracia. Las prácticas políticas y las acciones económicas han estado encaminadas a demostrar que es posible construir una democracia en la que los ciudadanos sean libres y autónomos, y los Estados independientes.

Delimitar históricamente la cuestión de la democracia es fundamental para comprender su injerencia en nuestra América Latina, así como definirla, para poder entender su dinamicidad:

La democracia es una utopía, un ideal a alcanzar y a establecer en una sociedad determinada.

Pero no es una utopía estructurada en un solo modelo político, sino que a lo largo de la historia se han planteado y se plantean distintos modelos de democracia (Gómez Leyton, 2004, p. 20)

América Latina se interna en el mar proceloso del discurso democrático y democratizador, quiere que sus ciudadanos sean libres y autónomos, que pasen de ser vasallos a ser ciudadanos (Cortina, 1997), se inserta en un proyecto político-cultural en el que quiere salir de la noción de encomendado a ciudadano, aspecto que se convierte en una utopía, que retoma elementos de los países europeos para armar un sueño democrático con modelos extranjeros, pero que al mismo tiempo exigen que para comprender la democracia "nos inclinamos por precisar un modelo analítico histórico de la democracia, más que referirnos a cómo debiera ser la democracia o cómo debió haber sido, sino resueltamente a lo que fue en la práctica histórica." (Gómez Leyton, 2004, p. 20) 
Por tal razón, hay que tener en cuenta que la teoría de la democracia se desarrolla polemizando, problematizando la forma de gobiernos monárquicos, teocéntricos, así como el absolutismo de esencia hobbesiano y que caracterizan a Europa entre el XVII y XVIII. Es en una discusión con la monarquía en la que surge la democracia, la teorización moderna de la democracia (Gómez Leyton, 2013). La democracia se preocupa por cómo los actores van a constituir algo que le tenían negado a la ciudadanía como era constituir y ser agente activo en la construcción del gobierno, de hecho en América Latina en la época de la conquista y la colonia, no era posible participar del gobierno y su constitución, ya que todo dependía de la monarquía regentada por la Corona Española. Este hecho es una ruptura con lo tradicional monárquico que lo mostraba como la mejor forma de gobierno y la más conveniente para América Latina. De tal manera que "los países latinoamericanos, desde el siglo XIX, han apelado a la historia y la cultura nacional en algunos casos con un fuerte contenido democrático" (Magallón Anaya, 2003, p. 85)

La ruptura que esto implica es la gestación de revoluciones y violencia, lo cual se puede evidenciar en los movimientos libertarios del siglo XIX en América Latina, específicamente. En Europa es el caso de Inglaterra en 1642, separando lo divino y monárquico porque el Gobierno lo instalan los hombres, los sujetos (Gómez Leyton, 2013). La revolución e independencia Norteamericana implanta la nueva idea, donde los hombres de forma libre y con ciertos mecanismos organizan su poder y gobierno. La nueva soberanía es la ciudadanía. Por eso la democracia aparece peleándose con la monarquía y los absolutismos, y pelea con el concepto moderno de Estado. Los sujetos se quieren cuidar por sí solos, ideal de la revolución de 1879 en Francia, decapitando los líderes monarcas. Se impone que los gobiernos, no todos, son electos. Lo que viene luego es la amplitud en la participación de todos en el gobierno, lo cual genera revoluciones como la de 1848, se busca el derecho al sufragio, la ciudadanía no se quiere quedar fuera, lo que fue resistido por aquellos que hacían parte del poder y que lo iban perdiendo por el sistema igualitario, al pasar del voto censitario al voto electoral. Esto quiere decir que América Latina se une al proceso democratizador moderno en el que se sumerge Europa, lógicamente con unas diferencias significativas, como lo es por ejemplo que el proceso europeo es hijo de la modernidad, mientras que en América Latina se da por el deseos de las élites de tener el poder, en un contexto más de modernización instrumental e industrial que de mentalidad moderna de progreso y cambio.

En este panorama se inserta el proyecto latinoamericano, en el que "la fracción burguesa más dinámica, fuertemente monopólica y asociada al capital extranjero, reestructurada y fortalecida además por la masiva venta de activos públicos a precios irrisorios, será la que hegemonizará el nuevo proyecto" (Osorio, 2010, p. 69) La constitución y construcción de los modelos democráticos y democratizadores en América Latina, además de seguir dependiendo de fuera, se unen a un sistema que debe responder a un paradigma, el cual es resumido en los siguientes principios para que una sociedad sea llamada o considerada democrática: 
1. un origen democrático, o sea, que la génesis de las normas institucionales, plasmadas por lo general en una constitución política, haya sido generada democráticamente a través de un acto constituyente democrático;

2. competencia política y existencia de oposición;

3. sufragio universal y otras formas de participación;

4. elecciones libres, competitivas y a intervalos de tiempo regulares;

5. electividad de todos los cargos más relevantes;

6. partidos en competencia;

7. fuentes de información diversas y alternativas;

8. duración legal de los cargos electos;

9. sometimiento de las Fuerzas Armadas al poder civil;

10. un demos votante claramente establecido (Gómez Leyton, 2004, pp. 23-24)

El sistema democrático y democratizador en América Latina se ha matriculado dentro de los referentes paradigmáticos y los modelos utópicos establecidos por los países llamados "desarrollados", la apuesta latinoamericana debe estar cifrada y medida por una serie de nuevos valores que son de compleja comprensión dentro de las acciones políticas, sociales y económicas en los Estado del Nuevo Mundo. La historia de América Latina ha estado acompañada de hechos que la hacen ser distinta y diferente, con relación a otras regiones del mundo. En cuanto a dichos procesos se refiere, de tal forma que:

es un hecho que actualmente son muy pocos los países que, a pesar de la tercera ola democrática, o el triunfo de la democracia liberal a nivel mundial, son democracias plenas, es decir, que cumplen cabalmente con los 10 requisitos antes señalados. Por ejemplo, en América Latina tan solo Costa Rica y Uruguay tendrían esa condición. El resto de los países de la región tendría algunas dificultades para cumplir con uno o más de esos requisitos (Gómez Leyton, 2004, p. 24)

Pero, ¿de dónde surgen esas dificultades para cumplir con tales requisitos? Como se puede evidenciar en la anterior afirmación de Gómez Leyton, los principios del modelo democrático se pueden aplicar a cualquier país del mundo que asuma tal condición, desde sus discursos, documentos nacionales y prácticas políticas. En todo este aspecto se debe tener en cuenta que la democracia genera conflictividad en cualquier sistema, por su misma esencia revolucionaria. La democracia sin conflicto no es democracia. Quien suspende los conflictos son los sistemas autoritarios, ya que impone imperativamente, mientras que en la democracia todo entra en discusión, una democracia sin disensos, sin antagonismos, no es democracia. Es parte de la democracia llegar a acuerdos, la imposición de las cosas no es democracia. Cuando se discute, se analiza, se disiente, ahí hay democracia, por lo tanto la democracia es conflictiva (Gómez Leyton, 2013), esto la diferencia del autoritarismo, porque es en el autoritarismo donde no puede haber diferencia de opinión, es decir, mientras que el autoritarismo es homogeneizante, la democracia parte y se difunde dentro de procesos totalmente heterogeneizantes. Además 
dentro del autoritarismo hay más heterofobia, entendida esta como un miedo a los cambios, mientras que la democracia se plantea como cambio constante y continuo para adaptarse a los momentos históricos. Desde el momento en que los países latinoamericanos han decidido adentrase en el proceso democratizador, se han prometido ser defensores acérrimos de la democracia como único modelo para sus pueblos. Esto se puede evidenciar en el primer artículo de la Carta Democrática Interamericana que reza: "Los pueblos de América tienen derecho a la democracia y sus gobiernos la obligación de promoverla y defenderla. La democracia es esencial para el desarrollo social, político y económico de los pueblos de las Américas", aspectos que han estado acompañados y matizados por una dinámica que permitiera una resignificación y cambio que se encaminara "del Estado Paternalista y Protector al estado Eficiente, y del súbdito al ciudadano" (Osorio, 2010, p. 71)

Por otra parte los ideales de la democracia se enmarcan dentro de los procesos llamados de progreso y de desarrollo. América Latina, ha sido desde la conquista y la colonia, un territorio propicio para sostener las economías de los países "desarrollados", de tal forma que "la relación entre la economía latinoamericana y la economía mundial puede ser caracterizada por un doble movimiento: marginalización relativa e inserción subordinada" (Lechner, 1977, p. 46) de tal manera que la entrada den el sistema democrático, es equivalente a la entrada al sistema capitalista y de mercado con el supuesto beneficio de los países latinoamericanos, pero que en el fondo se trata de un proceso de expropiación y des-acumulación que "en esta óptica, la misma fuga precipitada de riquezas ocurrida en el momento de la emancipación no es más que el punto culminante de un largo proceso de des-acumulación: es el acto último con el que el conquistador concluye su misión civilizadora" (Cueva, 2004, p. 14). Esto quiere decir que, para que los países latinoamericanos pudieran entrar en el sistema democratizador universal, tuvieron primero que vender sus recursos, dejar y permitir la expropiación de sus bienes, así como pasar por el monstruoso fenómeno de la esclavitud y la violencia, qué proceso tan intenso e interesante, pero al mismo tiempo doloroso, tortuoso y se podría decir que sin terminación. No porque los países latinoamericanos hayan decidido hacer caso al proyecto eurocéntrico y norteamericanizante de la democracia, quiere decir que estos problemas se hayan difuminado y exterminado, por el contario son cada vez más fuertes dentro de los procesos sociales de los distintos países que buscan hacer realidad del ideal democrático. Hay algo que sí ha cambiado, pero que al mismo tiempo se ha mantenido, como es el determinante relacional mediado por lo económico (Lechner, 1977), además de adentrase en un proceso de países consumistas de la industria y la tecnología que se produce en los países "desarrollados", de tal forma que:

América Latina enfrenta un proceso de industrialización teledirigida cuya función principal consiste en reproducir las relaciones capitalistas de producción a escala de un sistema capitalista integrado mundialmente. (...) El proceso de industrialización es una cuestión política y tiene efectos políticos. Uno de ellos podría ser el surgimiento del nuevo Estado Autoritario vinculado a la internacionalización de las relaciones capitalistas de producción" (Lechner, 1977, p. 48) 
Así las cosas, la democracia en América Latina va de la mano con los procesos de industrialización, con los juegos de poder económico que impone el sistema capitalista, de tal manera que la burguesía va a ser la encargada, por medio de las élites sociales, de llevar a cabo un proceso de industrialización y de tecnificación, en el que los encomendados, pasan a ser súbditos y no se les cumple con la procesa de ser ciudadanos, o en el mejor de los casos, se les disfraza la ciudadanía otorgándoles el derecho al voto pero no el derecho a la participación en el poder. El concepto de ciudadanía hace que los Estado Democráticos nacientes, por medio de los gobiernos de turno y de los aparatos estatales, tengan en cuenta el carácter universal y universalizable del concepto de ciudadanía, que por naturaleza:

La ciudadanía sugiere una tensión permanente entre los diferentes componentes que articulan la identidad política y colectiva de los miembros de una sociedad democrática. En ese sentido, la ciudadanía configura un concepto de pretensión universal que encarnan individuos particulares, en el marco de una tensión que constituye la arena de conflictos abiertos y latentes. Esta pertenece al ámbito de lo simbólico mientras que el ciudadano concreto no puede ser reducido a la esfera de los símbolos (Caetano, 2006, p. 244).

El proceso de democratización en América Latina ha estado conjugado por factores como la industrialización teledirigida y la constitución y establecimiento de la ciudadanía, matizados al mismo tiempo estos elementos por dinamizarse dentro del esquema capitalista, como regente, limitante y condicionante de lo que se quiera llamar democrático a la luz de los países que se han destacado por ser colonizadores y conquistadores. Llama la atención que la democracia en América Latina es un fenómeno que se afirma desde los discursos pero que se niega en las prácticas político-sociales. Es resultado de las inconformidades frente a los dominios de los colonos y los conquistadores, pero al mismo tiempo es una respuesta eficiente frente a la nueva organización mundial, caracterizada porque:

El surgimiento del imperialismo a fines del siglo significa la constitución de un nuevo orden mundial en torno a los centros industriales. Es solo ex post, por la dinámica inherente a la división internacional del trabajo, que lo que era "atraso" se transforma en "subdesarrollo". Entendemos por "capitalismo subdesarrollado" la incapacidad estructural de los países latinoamericanos por desarrollar mediante sus propios recursos los medios de producción (bienes de capítal) que corresponden a los standars mundiales de la industrialización (Lechner, 1977, pp. 52 - 53)

A esto se le suma que:

En el ámbito institucional, hasta antes de ese período -el de la segunda guerra mundial- lo que se tenía era un pensamiento latinoamericano liberal equivalente a un sistema de ideas pre-científico y pre-moderno; un pensamiento que se basaba más en la especulación, la filosofía y la jurisprudencia que en el método científico occidental centrado en la observación y la predicción, hegemonizado por el positivismo como representante de las clases conservadoras y terratenientes. (Sotelo Valencia, 2005, pp. 32-33) 
El sistema de la conquista y de la colonia ya había dejado su huella con el abuso y la expropiación de bienes y de territorios, con el saqueo de recursos naturales y con haber colonizado las mentes de los naturales y de los mestizos, criollos y afroamericanos con el principio de dependencia y de baja autoestima, frente al hombre verdaderamente capaz de poder transformar el mundo y producir para su beneficio. Además de haber dejado un pensamiento y una forma de hacer ciencia al estilo de la cultura feudal, basada en la especulación. Así, "el subdesarrollo que en el siglo XIX es definido por la Revolución Industrial, en el siglo XX lo es por la Revolución científicotecnológica" (Lechner, 1977, p. 53). Así América Latina se adentra más en los procesos de democratización, pero con un aditamento cargado de contradicciones: quiere equipararse y responder a las exigencias de las sociedades capitalistas desarrolladas (Lechner, 1977) permitiendo el dominio y la incursión de un nuevo sistema de conquista y colonización basado y cimentado en una "dominación político-cultural", de tal forma que se entra en un proceso hegemónico en todos los ámbitos sociales de Latinoamérica, fenómeno que entró en crisis en los años 30 del siglo XX, lo que ocasiona el desmoronamiento del Estado Oligárquico implantado en el siglo XIX.

Se trataría de una crisis de hegemonía. La oligarquía ha perdido la dirección políticomoral de la sociedad y ni os sectores medios ni las masas populares tienen la fuerza de reemplazarla. La presión popular obliga a una ampliación del consumo y de la participación política, es decir plantea la compatibilidad de desarrollo económico y democracia como la nueva tarea, pero es incapaz de llevarla a cabo (Lechner, 1977, p. 57)

La apuesta latinoamericana frente a la crisis de la hegemonía es fomentar el reformismo, entendido este como "el intento fracasado de construir una hegemonía" (Lechner, 1977, p. 63) en donde "el Estado no puede ser más que la hegemonía externa y la dominación interna." (Lechner, 1977, p. 63), lo cual se da en un contexto en el que "las clases medias no tienen, por lo tanto, la autonomía económica y política para impulsar un proyecto nacional" (Lechner, 1977, p. 65). Esta posición y exposición de Lechner permite afirmar que es en este ámbito en el que la democracia y el autoritarismo se abren un espacio para confundirse en los procesos políticos, sociales y económicos en América Latina, presentándose con credenciales democráticas en el discurso pero con prácticas sociales que niegan tales principios, lo cual lleva a una re-significación y reubicación democrática:

Hay un punto en el cual queremos ser categóricos: los procesos de democratización no conducen en forma ineludible al establecimiento de sociedades, regímenes o Estados democráticos. Aunque sí pueden dar origen o establecer regímenes políticos semidemocráticos o democráticos propiamente tales, como fue la situación de España entre 1933-1939 y de Chile entre 1958-1970. Sin embargo el intenso conflicto político que en ambos países se desencadenó como consecuencia de la democratización de la sociedad y del régimen político condujo a la crisis de Estado existente (Gómez Leyton, 2004, p. 31)

Se suma así al problémico sistema y proceso democratizador de América Latina, el concepto de régimen político, el cual se comenzó a cimentar desde el liberalismo como doctrina que 
sostiene esas revoluciones de independencia, tensionan y conflictúan el pensamiento y la acción política del proyecto emancipador colonial, como la institución de las constituciones políticas que van a regir al estado-nación y a las ciudadanías poscoloniales. El problema central consistía en que las élites eran parcialmente modernas, pero más que parcialmente modernas estaban encubiertas con una máscara de modernidad, es decir aparentaban ser modernas y no lo eran, fundamentalmente las élites aparentaban la modernidad porque querían aparecer como sujetos políticos que estaban haciendo un cambio trascendental en la política Latinoamérica, sin embargo, en su interior sentían un poderoso miedo político y social a la manifestación política de otros sectores sociales como las masas populares (Gómez Leyton, 2013). Ese miedo de las élites políticas los llevó a expresarlo en constituciones políticas en donde se establecían las más amplias libertades y derechos ciudadanos, pero que dejaban pervivir el vasallaje y dominación. Las relaciones de dominación por ejemplo que se desarrollaban al interior de la hacienda se mantenían al interior de la hacienda al comienzo del siglo XX. Esto impidió y obstaculizó la constitución del sujeto libre que reclama toda modernidad. De ahí entonces que, el sociólogo René Zavaleta Mercado, siguiendo a Marx, (Gómez Leyton, 2013) sostiene que para el desarrollo del hombre libre es necesario que prevalezca el capitalismo y la democracia. Esto lleva a afirmar que la democracia y el capitalismo no se instalaron en el siglo XIX, especialmente a sus inicios. Las élites del poder llegaron a considerar innecesaria la democracia para AL. Se prolongaron los dominios de las élites gracias al prevalecimiento de la dominación, a punta de azote y ley, implantando el control en los distintos sectores sociales. Sin embargo, a finales del s. XIX y comienzos del s. XX la conformación de un proletario minero y urbano portuario, principalmente, implicó la conformación de esa fuerza primaria, es decir, hacia 1880 en los espacios mineros y portuarios comenzó a emerger el sujeto moderno, es decir, el sujeto político libre que comenzó a demandar la constitución de un orden político moderno, no sólo con base en el liberalismo, sino que tuvieron en cuenta otras teorías como el socialismo y el anarquismo (Gómez Leyton, 2013). Sin embargo, ese hombre libre constituido en esos espacios, no podía considerarse como un ciudadano político moderno porque era sujeto social pero no era actor político, todavía le faltaba volverse un actor social estratégico de poder. La no formación del hombre libre está directamente relacionada a las resistencias de las élites políticas latinoamericanas, a los postulados centrales de la modernidad. Las élites se han opuesto a los planteamientos del liberalismo y se resisten a establecer o reconocer la existencia de dos elementos rectores y modulares de la modernidad, y que esa resistencia hace que todavía la democracia liberal sea todavía una promesa en la región, la más simple de las democracias como es la liberal y representativa. Permanentemente es limitada y cohibida. Las élites de poder han impedido instalar los siguientes dos principios: la igualdad política, social y económica que debe existir entre las y los ciudadanos, pues ha sido AL desigual en esto, ha sido permanentemente desigual, no es solamente cosa del neoliberalismo, de tal manera que "esta América mestiza se encuentra además flotando, como nunca, a la deriva, sin un perfil histórico claro ni un proyecto político y económico que la definan." (Cueva, 2004, p. 8).

Así, el nacimiento y establecimiento de un estado democrático, desde la visión y concepción de Lechner debe cimentarse en una razón social, pues "sin referencia social, el Estado es 
mera forma de dominación" (Lechner, 1977, p. 68), aspectos que han caracterizado a las dinámicas socio-políticas de los países latinoamericanos, se ha fomentado una dominación y un autoritarismos, que en momentos históricos concretos se ha disfrazado de democracia para responder a exigencias externas y poder garantizar la estabilidad interna, de tal manera que "la crisis del Estado es una crisis de sentido" (Lechner, 1977, p. 70). No ha podido América Latina demostrar, por medio de la constitución de sus Estados, que es capaz de ser autónoma e independiente, de saber fraguar y jugar con las intencionalidades de las nuevas formas de conquista y de dominación, por el contrario ha hecho evidente que prevalece el autoritarismo como polo de racionalidades sociales, políticas, culturales y educativas.

Las racionalidades sobre las cuales se constituye y se construye el sistema autoritario y el democrático son totalmente distintas, divergentes en su esencia, pero parece, por lo que se ha desarrollado hasta aquí, que en la práctica no son tan disímiles como se enuncia desde la teoría, lo cual permite ver con claridad que "la situación latinoamericana es visualizada como un problema político" (Lechner, 1977, p. 75), pero que además se convierte en un eje problémico estructural en el que juega un papel preponderante el sistema económico establecido, el sistema de los mercados, el carácter hegemónico capitalista (Tourain, 1989), caracteres que se han asumido y asimilado a veces de manera sincrética, otras de forma ecléctica; unos aceleradamente, otros lentamente; unos con éxito, otros con fracasos, por lo que se puede afirmar que "la diversidad de los resultados obtenidos introduce naturalmente una transformación profunda en la escena latinoamericana." (Tourain, 1989, p. 23). Todos los países latinoamericanos, sin excepción, se han preocupado por encaminarse hacia el progreso, sinónimo de desarrollo y mejoramiento de la calidad de vida de los ciudadanos, pero esto matizado y conjugado con el juego de los poderes económicos y las élites. Así se genera un tipo de racionalidad en el que debe primar la seguridad, es decir, que los Estados latinoamericanos quieren tener una seguridad para el establecimiento y la continuidad de su sistema, razón por la cual estructuran su institucionalidad con base en la democracia, pero:

¿Qué seguridad ofrece la democracia? El debate sobre la democracia, al igual que gran parte del pensamiento político moderno gira en torno a la seguridad; o sea, responde a miedo sociales. Del miedo a la guerra y la violencia, al desamparo y la miseria surgen las tareas de la política: asegurar la paz, garantizar la seguridad física y jurídica (Estado de Derecho) y promover la seguridad económica (Estado de Bienestar). Junto a los peligros materiales hay otros, difusos y difíciles de nombrar. Percibimos amenazas veladas, pero tanto más violentas por cuanto nos sentimos entregados a ella sin protección. Este miedo, este abandono cuestionan el orden social. Queda planteada la cuestión del orden (Lechner, 1989, p. 45)

Ante el miedo a la inestabilidad y el desorden, la mejor repuesta era el Orden, así como algunos de los escudos de los países democráticos llevan emblemáticamente la palabra Orden, como es el caso de Colombia: "Libertad y Orden", aspecto que se suma al afán de entrar en un proceso democratizador caracterizado por estar inmerso dentro de un proceso de industrialización, en 
un esquema tecno-científico, con espíritu de desarrollo y de progreso, que ante todo buscan dar respuestas de libertad y de autonomía. Aunque es interesante y llamativo que el Orden va a ser más bien la forma nueva de reproducir los esquemas de la encomienda la conquista, bajo el sofisma de la democracia. El Orden es estar a la disposición de lo que plantea el sistema hegemónico, es hacer lo que esté de acuerdo con el sistema establecido, o mejor, el Orden establecido, de lo contrario se es enemigo y ahí es donde aparece la contradicción entre aparato democrático y su adhesión al autoritarismo, de tal forma que el Orden es la visión y la misión de los Estados Latinoamericanos, aspecto que en Colombia es bien latente hasta nuestros días. La democracia así entendida va a ser un mecanismo para hacer prevalecer el orden, para garantizar la seguridad económica y el bienestar de los ciudadanos, el problema es que se aplica para uso pocos, para las élites, es el proteccionismo de los capitales de la burguesía heredera del poder político que se le complejizó su acción política al no poder entrelazarla con el ejercicio económico y los procesos sociales. Es indispensable repensar el ejercicio y el sentido de la política en América Latina, pero entendida ésta como un eje estructural de la sociedad y la cultura, no como un simple mecanismo administrativo, donde "la refundación de la política es quizá llevar al Estado y a la sociedad la convicción de la necesidad de síntesis" (Calderón, 1987, p. 102)

La discusión entre autoritarismo y democracia, las prácticas sociales que de allí se deriven, así como los modelos culturales que desde allí se construyan, deben ser analizados, abordados y estudiados como dos formas de mantener un sistema hegemónico, un sistema que no se debe fragmentar, dada cuenta que en América Latina un sistema u otro lo que han hecho es velar una realidad, fortalecer un esquema económico de élites burguesas y capitalistas, cimentar más las diferencias socio-económicas, y, exportar modelos políticos que no han respondido a las dinámicas propias de lo que significa ser latinoamericano, Aún dependemos, a pesar de las promesas de autonomía, independencia y libertad.

\section{CONCLUSIONES}

Abordar los procesos sociales y políticos de América Latina desde el estudio del autoritarismo y la democracia, como dos modelos que han caracterizado la constitución de los Estados Latinoamericanos, permite dilucidar varios aspectos, que de forma curiosa han afectado la comprensión del ser latinoamericano, de lo que es el ejercicio político en la región, y de lo que significa constituir una sociedad y forjar una cultura.

La conformación e implantación de la encomienda, es el primer ejercicio autoritario que caracteriza a la historia de las ideas políticas en América Latina, pues a partir de este ejercicio que los señores colonos y los conquistadores infunden la idea en los naturales de que son esclavos y deben producir para que el señor aumente sus propiedades y bienestar. Esta práctica llevada a cabo en la colonia se heredó en los siguientes procesos políticos y sociales. Hay que resaltar que se pensaba antes que la encomienda era un sistema para 
evangelizar, pero como no lo ha demostrado García Hamilton (2011) más bien fue un sistema que inició como estamento económico y que luego le sumaron al encomendero la responsabilidad de evangelizar a los naturales de estas tierras.

Pero el sistema de la encomienda, así como las prácticas llevadas a cabo por los colonos y conquistadores, cansó con el tiempo a los naturales, de la misma manera que a los criollos, quienes en su élite culta y burguesa, gracias al contacto que habían tenido con las ideas de emancipación desde la Revolución Francesa, establecen los movimientos de emancipación y libertarios, de tal manera que con el tiempo lo que hicieron fue asumir los modelos europeos de organización, especialmente el modelo democrático, pero este proceso no fue asumido y llevado a cabo de la noche a la mañana, sino que fue construido de acuerdo con los procesos de cada país de la región. Así, se asumió el modelo democrático, se obstruyeron absolutismos al estilo de la Revolución Francesa, y se estableció una nueva burguesía, pero con un aditamento curioso: seguían dependiendo de países "desarrollados", de los que con anterioridad habían expropiado bienes y saqueado recursos, es decir, se pasó de una conquista territorial y de un saqueo de recursos, a una conquista de mercados, mentalidades e ideas hegemonizantes.

Con el paso del tiempo los países latinoamericanos caen tardíamente en cuenta que además de los procesos políticos, la sociedad europea está inmersa en un proceso de industrialización, tecnificación y cientificación de su cultura, aspectos que no se tuvieron en cuenta por las burguesías criollas porque la preocupación era mantenerse bien en lo económico, así les correspondiera la venta directa del país. A esto se le suma que la industrialización somete a los países en vías de desarrollo, de tal manera que se convierten en "subdesarrollados" porque no producen industria, condición que favorece un nuevo sistema de conquista y colonización, así como el fortalecimiento de la dependencia económica y política.

Los latinoamericanos le apostaron a la utopía de la democracia, pero con un aspecto original y propio de la región, que para ser democráticos lo mejor era llevar a cabo acciones autoritarias para mantener el orden establecido. En medio de todos estos avatares políticos, los Estado emergentes latinoamericanos optan por matricularse dentro del proceso de democratización, entendido éste también como un proceso inmerso dentro del sistema capitalista. No fue fácil asumir la responsabilidad de constituir un Estado democrático, sobre todo por los sistemas de pendencia y los miedos de os criollos de perder sus beneficios y bienes económicos, fenómeno que los llevó a construir una democracia divorciada de los procesos sociales, de la cultura y de la política.

Autoritarismo y democracia son una realidad dentro del proceso de construcción de la política latinoamericana, queda por ahora ahondar en el problema y estudiarlo de forma sistémica y holística, no fragmentada y disgregada de las dinámicas sociales y las connotaciones culturales del ser latinoamericano, dentro de las cuales están la educación y la paradigmática ciudadanía digital y sus relaciones con la educación y los procesos políticos contemporáneos. 


\section{REFERENCIAS}

- Caetano, G., (2006). Distancias críticas entre ciudadanía e instituciones. Desafíos y transformaciones en las democracias de I América Latina Contemporánea.. En: Sujetos sociales y nuevas formas de protesta en la historia reciente de América Latina. Buenos Aires: CLACSO, pp. 243 - 269.

- Calderón, F. y. D. S. M. (1987). Lo politico y lo social: bifurcación o síntesis en la crisis.. En: Socialismo, autoritarimos y democracia. Buenos Aires: CLACSO, pp. 89-106.

- Cortina, A. (1997). Ciudadanos del mundo: hacia una teoría de laq ciudadanía. Barcelona: Alianza.

- Cueva, A. (2004). El desarrollo del capitalismo en América Latina. 19a ed. México: Siglo XXI editores.

- Domínguez Nárez, F. (2004). Legitimidad y gobernabilidad en el autoritarismo. 1a ed. México: Universidad Juárez Autónoma de Tabasco.

- García Canclini, N. (1989). Culturas híbridas. Estrategias para entrar y salir de la modenidad. México: Grijalbo.

- García Hamilton, J. I. (2011). Autoritarismo e improductividad en Hispanoamérica. 5a ed. Bueno Aires: Sudamericana S.A.

- Gómez Leyton, J. C. (2004). La frontera de la democracia: el derecho de propiedad en Chile. 1925 - 1973. 1a ed. Santiago de chile: LOM.

- Gómez Leyton, J. C. (2013). Seminario debate: Entre democracia y autoritarismo en América Latina.. Santiago de Chile: Apuntes sesión Doctorado en Procesos Sociales y Políticos en Amérioca Latina.

- Lechner, N. (1989). ¿Responde la democracia a la búsqueda de certidumbre?. En: Socialismo, autoritarismo y democracia. Buenos Aires: CLACSO, pp. 45-70.

- Lechner, N. (1977). La crisis del Estado en América Latina. Caracas: Cid Editor.

- Magallón Anaya, M. (2003). La democracia en América Latina. 1a ed. México: Plaza y Valdés. 
- Osorio, J. (2010). Nuevo patrón de dominación en América Latina: ¿Autoritarismo o democracia?. América Latina, Issue 9, pp. 63-92.

- Sotelo Valencia, A. (2005). América LAtina: de crisis y paradigmas.. 1a. ed. México: Plaza y Valdés.

- Tourain, A. (1989). La crisis y las transformaciones del sistema político emn América Latina. En: Socialismo, autoritarismo y democracia. Buenos Aires: CLACSO, pp. 17-44. 